\title{
Geographic information system (GIS) analysis on the distribution of patients visiting at a dental college hospital: a pilot study
}

\author{
Hyun-Tae Joo', Byung-Joon Jeong ${ }^{2}$, In-Woo Cho², Hyun-Seung Shin², Mi-Hwa Lim³, Jung-Chul Park ${ }^{2 *}$ \\ ${ }^{1}$ Department of Urban Planning, Graduate School, Hanyang University, Seoul, Republic of Korea \\ ${ }^{2}$ College of Dentistry, Dankook University, Cheonan, Republic of Korea \\ ${ }^{3}$ Department of Urban Planning and Real Estate, Dankook University, Yongin, Republic of Korea
}

Purpose: The aims of this study are to analyze and to visualize distribution of patients visiting at a dental college hospital, using geographic information system (GIS). The visualized data can be utilized in patient care and treatment planning, ultimately leading to the assessment of risk evaluation and prevention of dental diseases. Materials and Methods: Patient information data was obtained from Dankook University Dental Hospital including the unit number, gender, date of birth, and address from 2007 to 2014. Patient distribution was visualized using GIS. Statistical analyses were performed using SAS 9.3 and ArcGIS 10.1. Five factors including proximity, accessibility, age, gender, and socioeconomic status were investigated as the explanatory variables of the patient distribution. Results: The visualized patient data showed a nationwide scale of the patient distribution. There was a little difference in characteristics for each department. As closer at Dankook University Dental Hospital, visitors increased. And it strongly showed that elderly patients in rural areas tend to visit more. Conclusion: The distribution of patients has been shown to be significantly affected by the proximity, accessibility, age, gender and socioeconomic status. The underlying reason remains to be further studied. (J Dent Rehabil Appl Sci 2015;31(4):283-93)

Key words: geographic information system; dental diseases; epidemiology

\section{서론}

Geographic information system (GIS, 지리 정보 체계) 란 지리적 정보의 분석과 이를 지도화하는데 이용되는 컴퓨터 기반의 도구를 통칭한다. ${ }^{1}$ 최근 지리 정보 체계와 공간 분석의 발전, 공간적 데이터의 접근성 향상으로 인 해 이러한 도구를 이용하여 이전에는 불가능했던 질병 역학의 지리 공간적 연구가 가능하게 되었다. ${ }^{2,3}$ 또한 GIS 는 개개인을 환경과 연결시켜 특정 질환에 이환된 환자 들의 공간적 분포에 대한 이해를 높힐 수 있어, 최근 GIS 관련 기술의 발전으로 인해 다양한 학문 분야에서 접목

*Correspondence to: Jung-Chul Park

Professor, Department of Periodontology, Dankook University College of Dentistry, 119 Dandae-ro, Dongnam-gu, Cheonan, 31116, Republic of Korea Tel: +82-41-550-1931, Fax: +82-303-3442-7364, E-mail: periopark@dankook.ac.kr Received: July 6, 2015/Last Revision: September 8, 2015/Accepted: September 14,2015
이 시도 되고 있다. ${ }^{4-6}$

국내 의료계에서는 GIS를 이용한 연구가 일부 진행된 바 있으나 응급 의료 시스템, 전달 체계나 진료권 분석에 대한 연구에 제한되었다..$^{7-9}$ 최근에는 주로 의료서비스에 대한 접근성이나 의료 취약 지역 분석을 위해 GIS가 활 용되고 있다. ${ }^{10,11}$ 치과영역에서도 최근 들어 공간 분석을 위해 GIS를 적극적으로 활용하기 시작하였는데, 그 예 로서 치과의사 대 인구 비, 지역별 구강암의 발병률, 치 과적 응급 상황에서의 이동 패턴 등의 많은 연구에 GIS 가 적용된 바 있고, 이를 통해 학술적, 임상적으로 활용 할 수 있는 유의미한 결과들이 많이 도출되었다. ${ }^{4,12,13}$ 하

Copyright(C 2015 The Korean Academy of Stomatognathic Function and Occlusion. (c) It is identical to Creative Commons Non-Commercial License. 
지만 이러한 연구들은 치과 질환의 발병률이나 환자의 접근성 분석에 국한되어 있었고 국내에서도 치과계에서 GIS 연구를 시행한 바 있으나, ${ }^{14,15}$ 지리적인 측면에서의 치과 질환의 위험 요인이나 각 전문 과목 별 환자의 지 리적 특성에 대해서는 아직 연구된 바가 없다.

이에 저자들은 치과 질환에서의 위험요인으로써 지리 적 요인이 의미를 갖는 것으로 가정하고, 치과의 각 전 문 과목 별로 환자의 거주지 지리적 특성이 다를 것으 로 가설을 세웠다. 따라서 본 연구의 목적은 대학병원 부속 치과병원에 내원한 환자들의 시각화된 분포의 패 턴을 분석하고, 이를 통해 부가적인 병인론적 가설을 도 출하기 위한 근거 자료를 확보하고자 하는 것이다. 이처 럼 시각화된 지리 정보 자료는 향후 개선된 환자 관리와 치료 계획에 반영될 수 있을 것이며, 궁극적으로 양질의 치과 진료를 공급하고 치과 질환을 예방하는데 많은 기 여를 할 것이다.

\section{연구 재료 및 방법}

단국대학교 부속 치과대학병원에 2007년 이후 내원한 환자의 동 단위 이상 정보를 토대로 연구를 진행하였다. 개인사생활 보호를 위해 철저하게 개인 식별 정보를 삭 제한 상태로 데이터 분석을 시행하였고 이러한 연구의 윤리성 문제는 단국대학교 치과대학병원 IRB를 통해 검 토 받았다(IRB no. H-1501/001/004).

본 연구에서는 단국대학교 부속 치과병원의 각 과별 환자 수를 종속변수로 하여 행정동별 남성비율, 평균연 령, 톨게이트까지의 거리를 독립변수로 회귀분석을 진 행하였고, 방문자수의 특성을 변수로 하여 자료를 구축 하였다. 공간회귀분석을 진행하기 위해서 각 행정동 기 준으로 환자 수, 남성비율, 평균 연령을 독립변수로 하여 공간지리가중회귀분석을 진행하였다.

단국대학교 치과병원의 구강내과, 구강악안면외과, 소아치과, 치과교정과, 치과보존과, 치과보철과, 치주과 의 방문 환자 수와 지역별 방문환자의 성비 및 평균 연 령을 통하여 다음과 같은 분석을 진행하였다. 지역은 전 국의 행정동 단위로 구분하였으며, 각 지역에서 병원까 지의 거리는 각 행정동의 중심점에서 단국대학교 치과 병원까지의 직선 거리를 이용하였다. 또한 고속도로 입 구까지의 거리도 각 행정동의 중심점에서 가장 가까운 고속도로 입구까지의 직선거리를 이용하였다. 지역의 평균 환자 연령은 각 과별 방문환자 연령의 평균이며, 남
성환자 비율은 각 지역의 전체 환자 중 남성의 비율을 이용하였다. 지역의 평균 개인소득은 동별로 구할 수가 없기 때문에 통계청의 시도별 개인소득 자료를 이용하 였다. ${ }^{16}$

회귀분석의 모형은 식1과 같다.

$$
\mathrm{Y}_{\mathrm{i}}=\alpha_{\mathrm{i}}+\beta_{1 \mathrm{i}} \mathrm{D}_{1 \mathrm{i}}+\beta_{2 \mathrm{i}} \mathrm{D}_{2 \mathrm{i}}+\beta_{3 \mathrm{i}} \mathrm{A}_{\mathrm{i}}+\beta_{4 \mathrm{i}} \mathrm{S}_{\mathrm{i}}+\beta_{5 \mathrm{i}} \mathrm{I}_{\mathrm{i}}+\varepsilon_{\mathrm{i}} \text { 식 } 1
$$

공간지리가중회귀모형은 인접한 지역의 특성의 변화 에도 영향력을 받을 수 있다고 가정하고, 이러한 영향력 을 통제하기 위해서 주변지역들이 종속변수에 미치는 영향력을 변수화하여 새로운 설명변수로 회귀분석에 적 용하여 식2와 같이 나타낼 수 있다.

$$
\mathrm{Y}=p \mathrm{~W}_{1} \mathrm{Y}+\mathrm{X} \beta+\varepsilon
$$

$p \mathrm{~W}_{1} \mathrm{Y}$ 을 좌항으로 이항하면 아래의 식3과 같이 나타 낼 수 있으며,

$$
\mathrm{Y}=\left(1-p \mathrm{~W}_{1}\right)^{-1} \beta \mathrm{X}+\left(1-p \mathrm{~W}_{1}\right)^{-1} \varepsilon
$$

본 연구에서 사용된 공간지리가중회귀분석 모형은 식 4와 같이 나타낼 수 있다.

$$
\begin{aligned}
\mathrm{Y}_{\mathrm{i}} & =\left(1-p \mathrm{~W}_{1}\right)^{-1} \beta_{1 \mathrm{i}} \mathrm{D}_{\mathrm{i}}+\left(1-p \mathrm{~W}_{1}\right)^{-1} \beta_{2 \mathrm{i}} \mathrm{A}_{\mathrm{i}} \\
& +\left(1-p \mathrm{~W}_{1}\right)^{-1} \beta_{3 \mathrm{i}} \mathrm{S}_{\mathrm{i}}+\left(1-p \mathrm{~W}_{1}\right)^{-1} \beta_{4 \mathrm{i}} \mathrm{I}_{\mathrm{i}} \\
& +\left(1-p \mathrm{~W}_{1}\right)^{-1} \varepsilon
\end{aligned}
$$

위의 식1과 식 4에서 $\mathrm{Y}_{\mathrm{i}}$ 는 각 과별 방문 환자 수, $\mathrm{D}_{1 \mathrm{i}}$ 는 지역 중심에서 병원까지의 직선거리, $\mathrm{D}_{2 \mathrm{i}}$ 는 지역 중심에 서 고속도로 입구까지의 거리, $\mathrm{A}_{\mathrm{i}}$ 는 각 과별 지역의 평균 환자 연령, $\mathrm{S}_{\mathrm{i}}$ 는 각 과별 지역의 남성 환자 비율, $\mathrm{I}_{\mathrm{i}}$ 는 각 과별 지역의 평균 개인소득이다.

본 연구에서 사용된 변수는 다음과 같다. 종속변수로 는 각 행정동 기준의 과별 방문자 수이며, 접근성을 알 아볼 수 있는 병원에서 방문자가 거주하는 행정동의 중 심지까지의 직선 거리와 방문자가 거주하는 행정동의 중심지에서 가장 가까운 톨게이트 입구까지의 직선거 리, 환자의 특성을 볼 수 있는 방문 환자의 평균연령, 남 성비율, 1 인당 평균 소득을 독립변수로 사용하였다. 거 리의 기준을 행정동의 중심지까지로 한 것은 개인정보 보호로 인하여 환자의 거주지 주소를 행정동까지 취득 할 수 밖에 없기 때문이며, 또한 1인당 평균 소득은 통계 청에서 시도 단위로만 제공하고 있기 때문에 시도 단위 의 자료를 이용할 수 밖에 없었다.

Shin 등의 연구에서는 외래의료서비스 접근성 요인 
을 알아보기 위해서 교통시간, 균등화 소득, 나이, 교육 수준, 직업 등의 변수를 사용하였으며, ${ }^{10}$ 본 연구에서는 접근성을 알 수 있는 변수로 교통시간 대신 직선 거리를 이용하였다. 또한 환자 특성으로는 취득 가능한 범위내 의 변수인 성별과 연령 등을 이용하였다.

\section{종속변수 각 과별 방문자 수}

독립변수 병원(단국대학교 치과대학부속병원)에 서 방문자가 거주하는 행정동의 중심지 까지의 직선 거리

방문자가 거주하는 행정동의 중심지에 서 가장 가까운 톨게이트 입구까지의 직 선거리

방문 환자의 평균 연령(행정동 기준) 방문 환자의 남성 비율(행정동 기준) 1 인당 평균 소득(시/도 기준)

\section{결과}

시각화된 환자 자료 분석 결과 환자의 내원은 전국적 인 분포 양상을 나타났고, 과별로 상이한 양상이 관찰되 었다. 치주과나 구강악안면외과의 경우 다른 과들에 비 해서 훨씬 더 전국적인 환자 분포가 나타났다. 반면, 치 과교정과는 매우 국소적인 지역 분포를 보였으며, 이는 수년간 자주 내원해야 하는 과의 진료 특성에 의한 영향 인 것으로 생각된다. Fig. 1 부터 Fig. 7 은 각 과별 공간지 리가중회귀분석을 실행한 결과이며, 대부분의 과에서 단국대학교 치과병원이 있는 천안시 동남구 신부동의 일정거리 이상의 남북쪽에서 방문 환자수가 양의 영향 력을 보이고 있는 형태를 나타내고 있다. 이는 공간적인 형태에서 천안시 외부에서 오는 방문객의 수가 많은 것 으로 판단된다. 다만 치과교정과 및 치과보존과에서는 천안시내 지역에서의 방문 환자의 수도 높은 것으로 나 타나 과별 특성에 따른 차이로 판단된다.
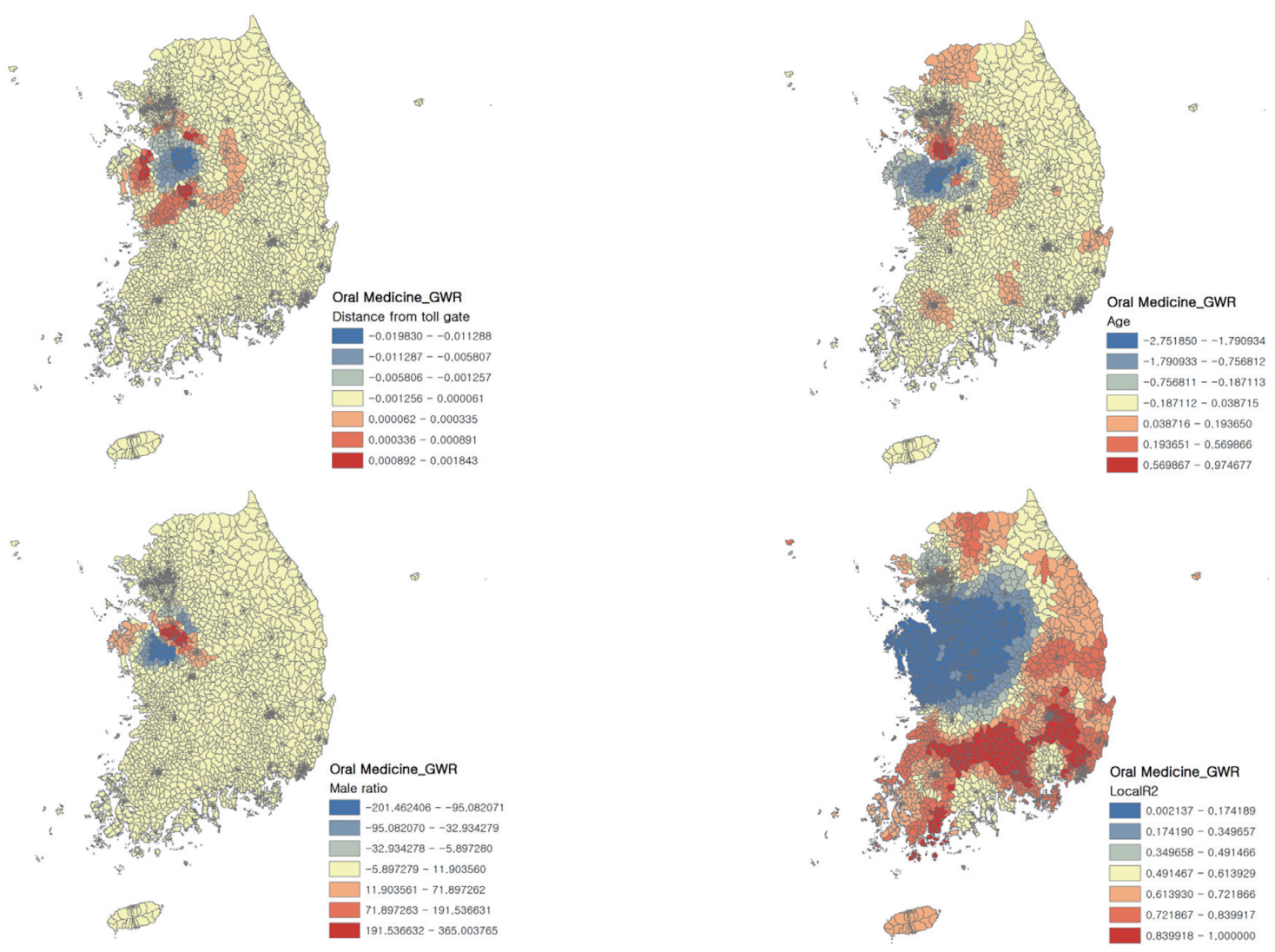

Fig. 1. Color coded local R-square of oral medicine. 

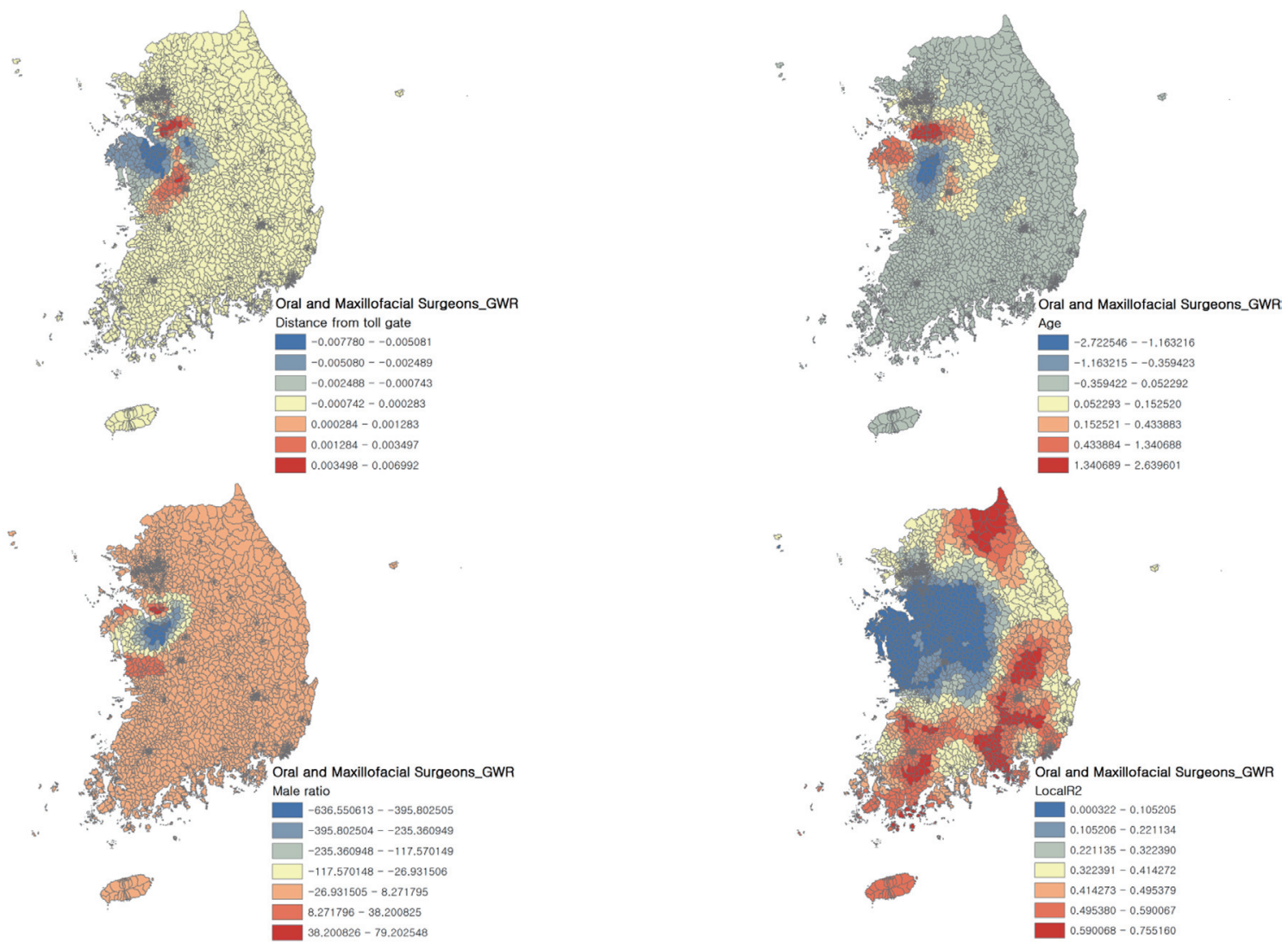

Fig. 2. Color coded local R-square of oral maxillofacial surgery.
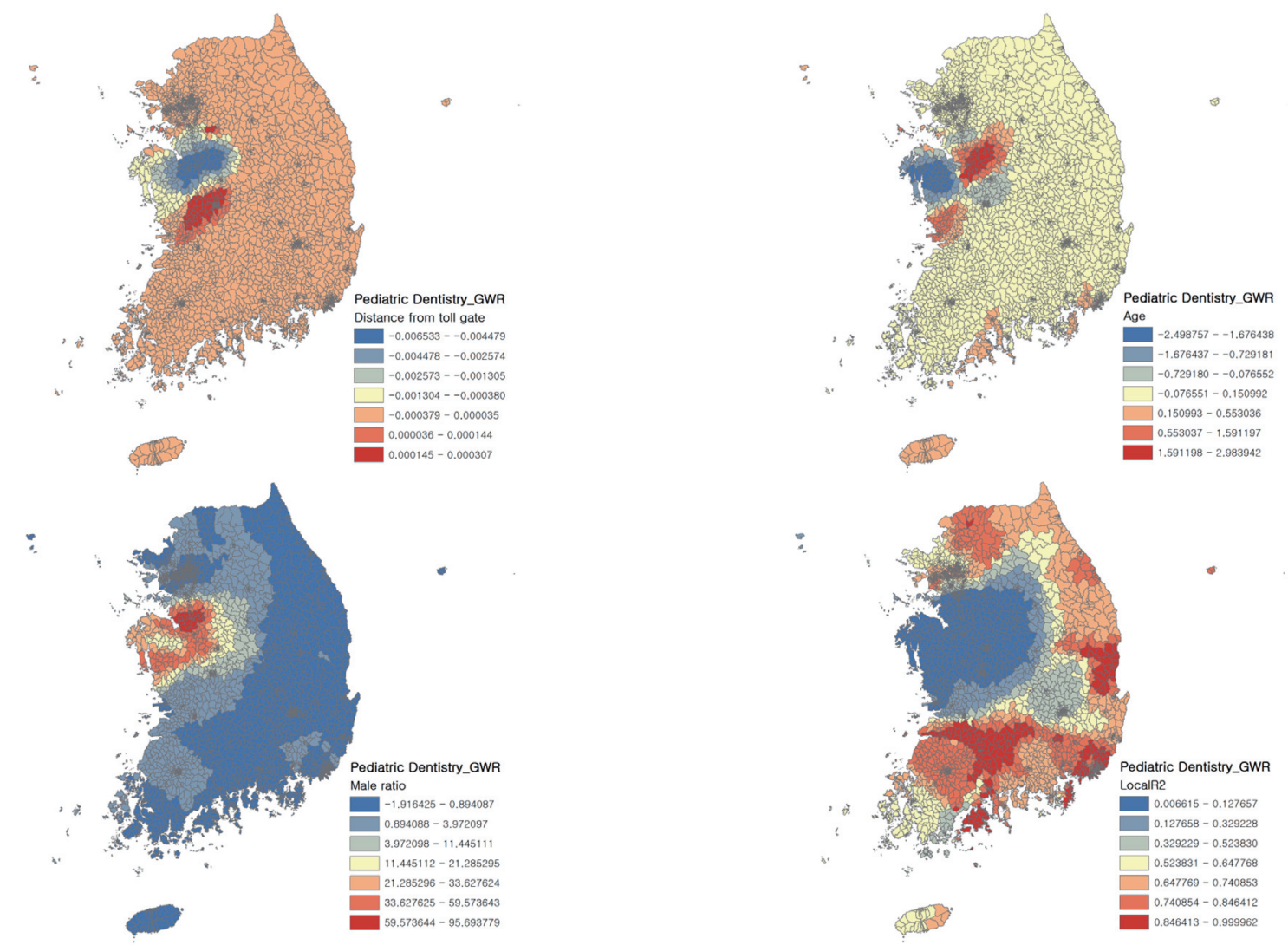

Fig. 3. Color coded local R-square of Pediatric dentistry. 

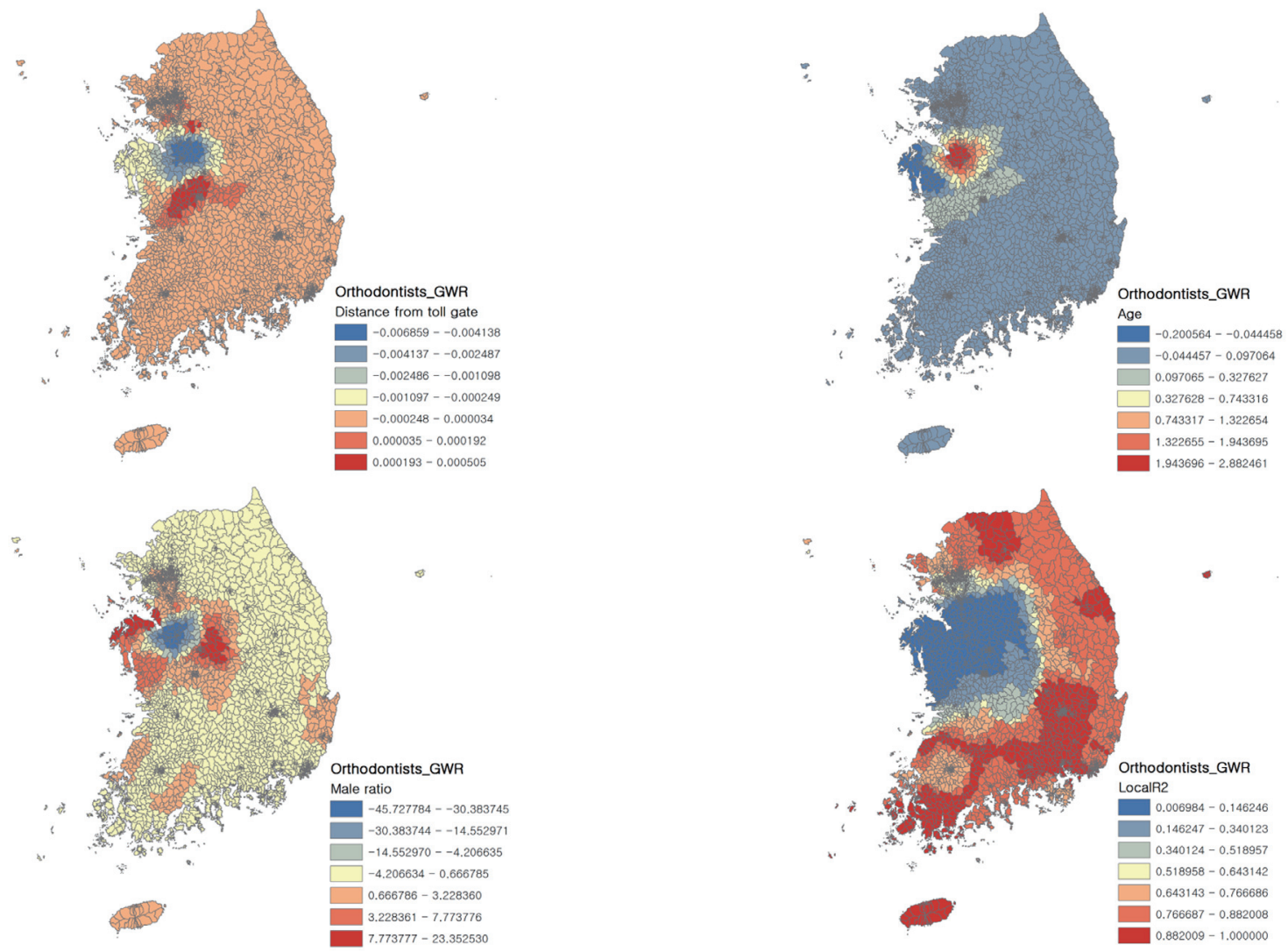

Fig. 4. Color coded local R-square of orthodontics.
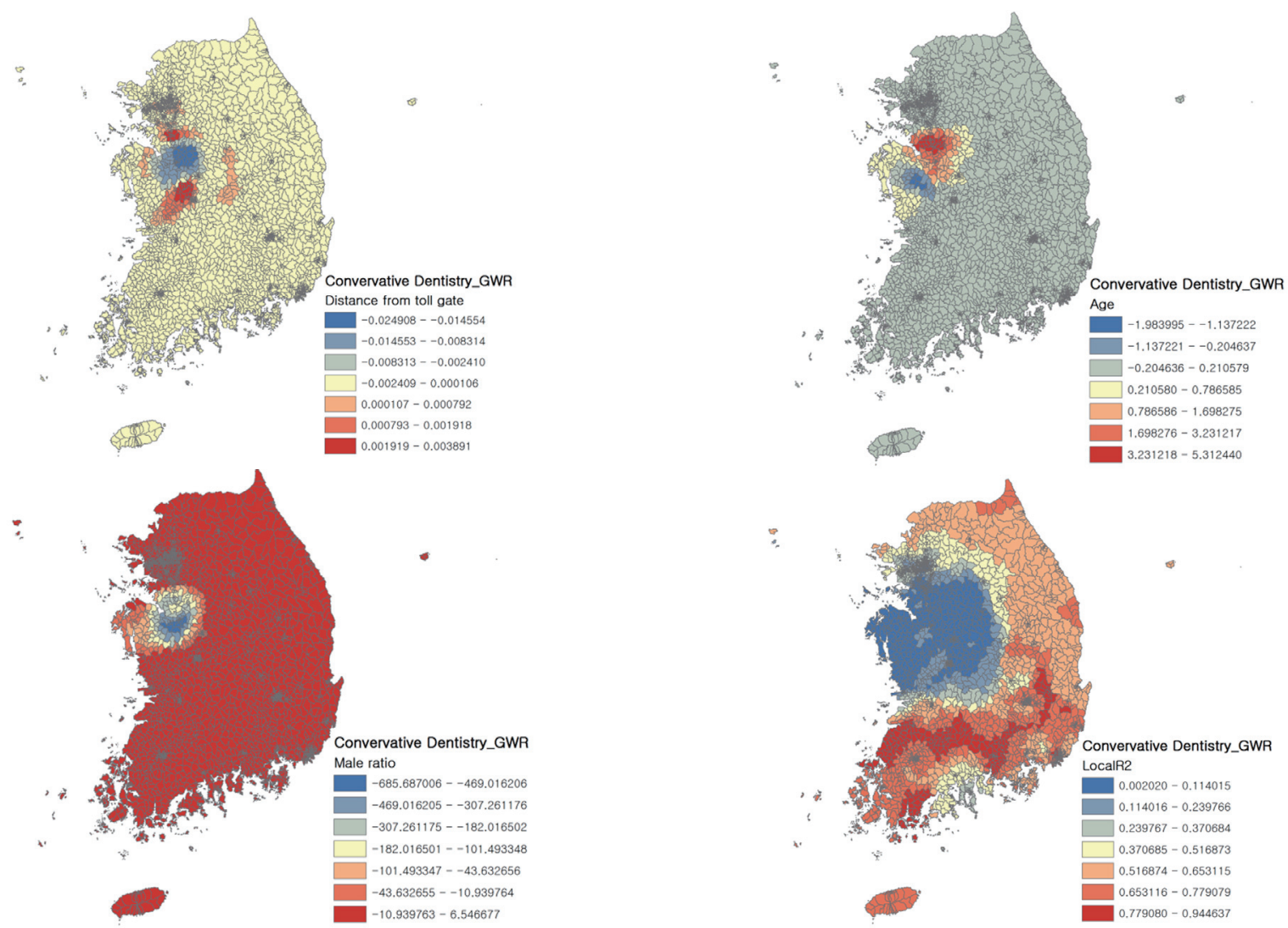

Fig. 5. Color coded local R-square of conservative dentistry. 


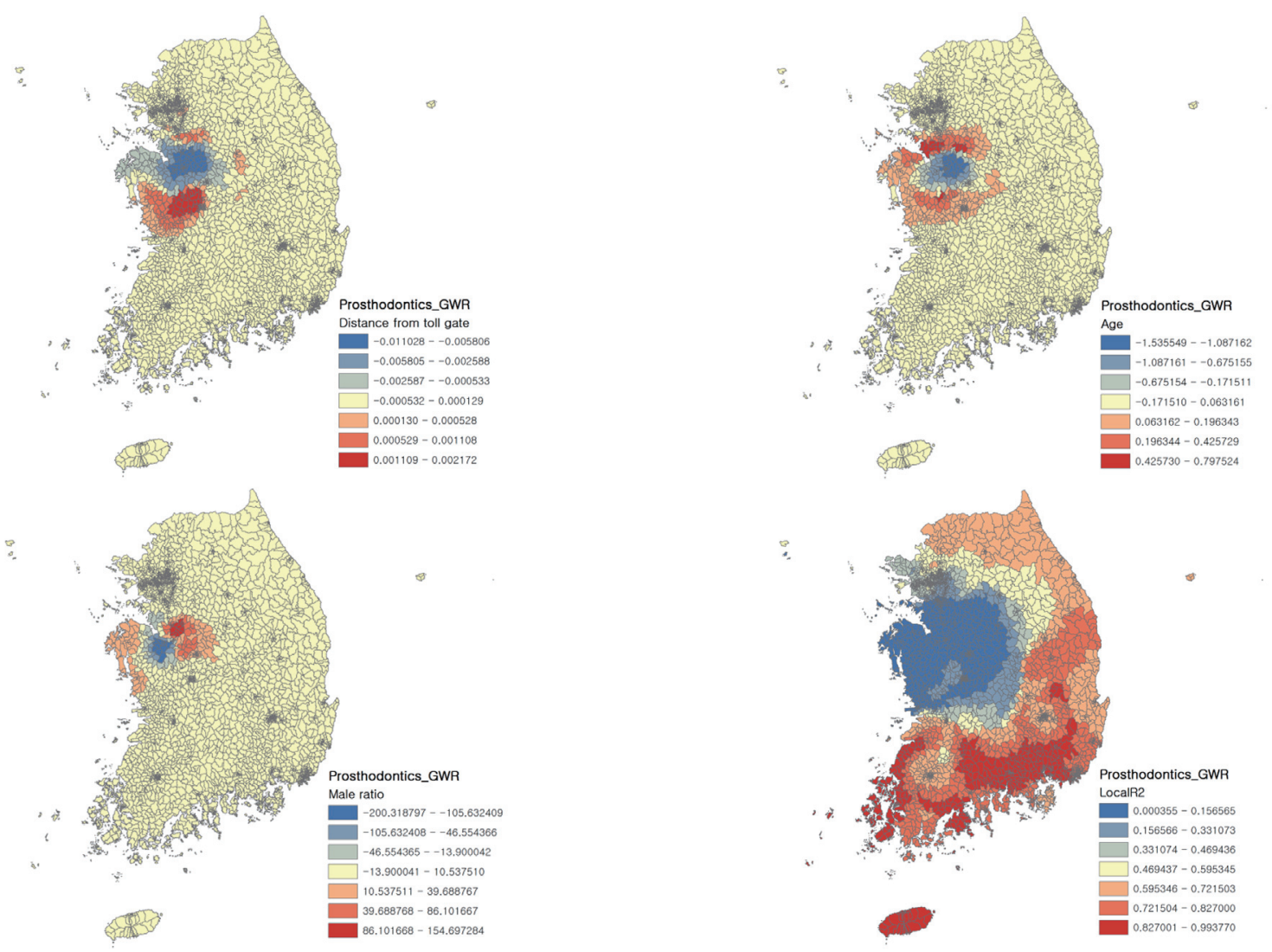

Fig. 6. Color coded local R-square of prosthodontics.
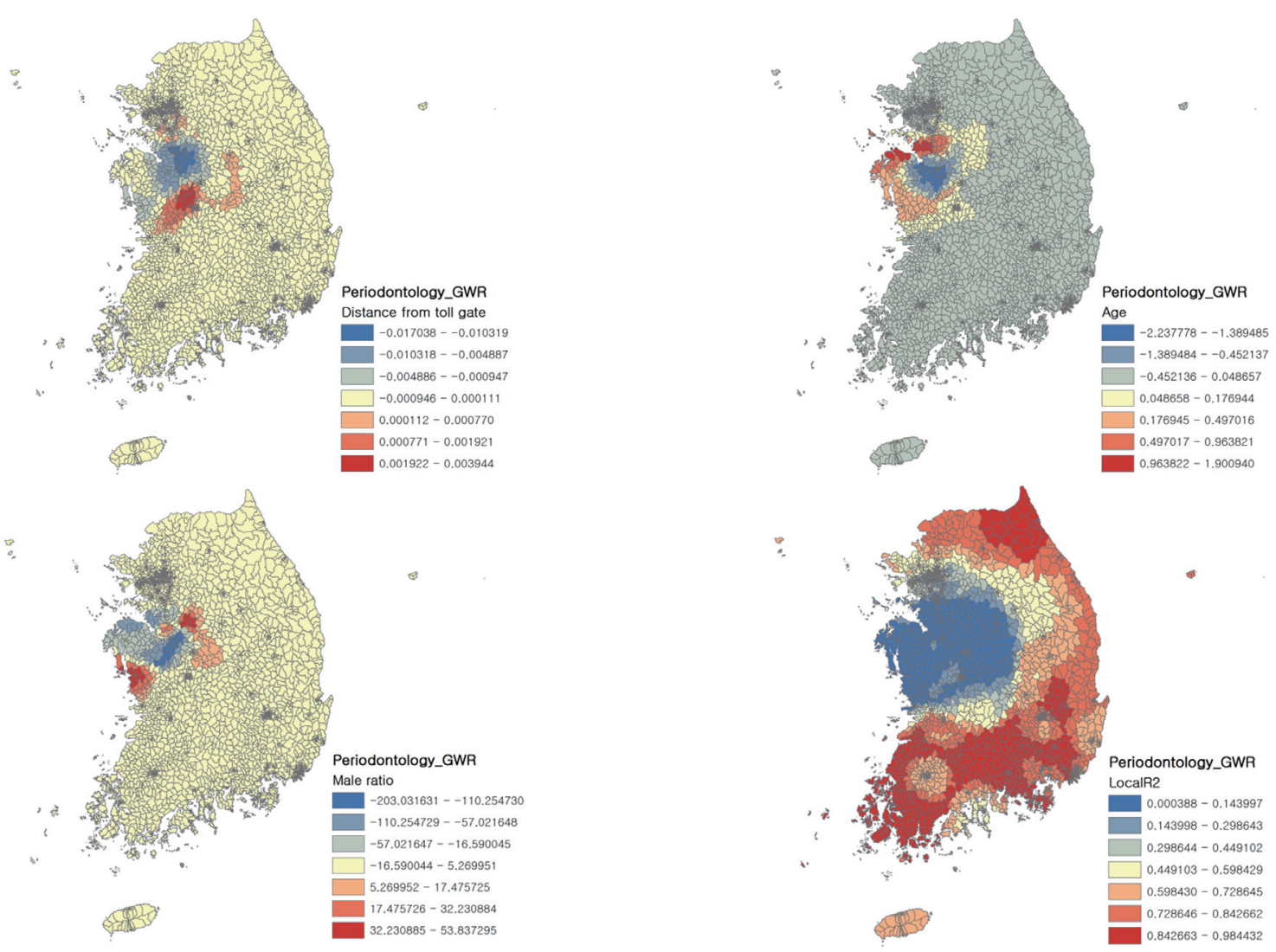

Fig. 7. Color coded local R-square of periodontology. 
Table 1 의 회귀분석 결과를 보면 치과보존과를 제외 한 모든 과에서 병원에서 지역중심점까지의 거리에 모 두 유의한 영향력을 보이고 있으며, 방향성도 음의 방향 으로 거리가 멀어질수록 방문환자 수가 줄어드는 것으 로 나타났다. 치과보존과를 제외한 모든 과에서 톨게이 트까지의 거리는 대상지 주변에서 거리가 증가할수록 방문자수가 감소하고, 고속도로입구에서 중심점까지의 거리가 유의한 차이를 보이는 것으로 나타났다. 고속도 로입구가 일반적으로 번화한 도시와 가까운 점을 고려 한다면 단국대학교 치과병원의 방문 환자들은 번화한 도시가 아닌 고속도로 입구에서 멀리 떨어진 지역에 거 주하는 환자일 것으로 판단된다.
연령평균 변수의 경우에는 치과교정과와 치과보존과 를 제외하고는 시 외곽에서 나이가 증가할수록 양의 방 향성으로 유의한 영향력을 보여 방문자 수가 증가하는 것으로 나타났다. 따라서 치과교정과와 치과보존과를 제외하고는 나이가 증가할수록 방문자 수가 증가하는 것으로 관찰되었고, 이는 치과교정과의 경우 특정 연령 대의 환자가 많고, 치과보존과에서는 다양한 종류의 치 료를 하고 보존적인 치료는 나이에 상관 없이 많은 환자 들이 방문하기 때문인 것으로 판단된다. 남성의 비율은 소아치과, 치과교정과에서 유의한 영향력을 보이고 있 으며 모두 여성 환자에 비해서 남성 환자일 경우 방문환 자 수가 증가하는 경향을 보이고 있다. 마지막으로 개인

Table 1. Regression analysis of the patients in the Dankook University Dental Hospital

\begin{tabular}{|c|c|c|c|c|c|c|c|c|}
\hline \multicolumn{2}{|c|}{ Department } & Oral medicine & $\begin{array}{c}\text { Oral and } \\
\text { maxillfacial } \\
\text { surgery }\end{array}$ & $\begin{array}{l}\text { Pediatric } \\
\text { dentistry }\end{array}$ & Orthodontics & $\begin{array}{c}\text { Conservative } \\
\text { dentistry }\end{array}$ & Prothodontics & Periodontology \\
\hline \multicolumn{2}{|c|}{ Intercept } & $53.83510^{* * *}$ & $96.18716^{* * *}$ & $34.57532 * * *$ & $21.77803^{* * *}$ & 81.87594 & $50.45389 * * *$ & $59.40486^{* * *}$ \\
\hline \multirow{2}{*}{$\begin{array}{l}\text { Distance } \\
\text { from center } \\
\text { of region to } \\
\text { hospital }(\mathrm{km})\end{array}$} & $\begin{array}{l}\text { Parameter } \\
\text { Estimate }\end{array}$ & $-0.11952 * * *$ & $-0.21739 * * *$ & $-0.07471 * * *$ & $-0.04256^{* * *}$ & -0.17345 & $-0.10644 * * *$ & $-0.12012 * * *$ \\
\hline & $\begin{array}{l}\text { Standardized } \\
\text { Estimate }\end{array}$ & -0.22923 & -0.25368 & -0.16630 & -0.17985 & -0.20806 & -0.22935 & -0.22045 \\
\hline \multirow{2}{*}{$\begin{array}{l}\text { Distance } \\
\text { from adjacent } \\
\text { toll gate to } \\
\text { center of } \\
\text { region }(\mathrm{km})\end{array}$} & $\begin{array}{l}\text { Parameter } \\
\text { Estimate }\end{array}$ & $0.12346 * * *$ & $0.22055^{* * *}$ & $0.07176^{* *}$ & $0.04171 * * *$ & 0.17231 & $0.11253^{* * *}$ & $0.12489 * * *$ \\
\hline & $\begin{array}{l}\text { Standardized } \\
\text { Estimate }\end{array}$ & 0.06716 & 0.07300 & 0.04531 & 0.04999 & 0.05863 & 0.06877 & 0.06501 \\
\hline \multirow{2}{*}{ Age } & $\begin{array}{l}\text { Parameter } \\
\text { Estimate }\end{array}$ & $0.16098 * * *$ & $0.26596 * * *$ & $0.31915^{*}$ & $0.20912^{* * *}$ & 0.37293 & $0.13357^{* * * *}$ & $0.20156^{* * *}$ \\
\hline & $\begin{array}{l}\text { Standardized } \\
\text { Estimate }\end{array}$ & 0.08205 & 0.08100 & 0.03970 & 0.13000 & 0.12628 & 0.09584 & 0.12197 \\
\hline \multirow{2}{*}{ Male ratio } & $\begin{array}{l}\text { Parameter } \\
\text { Estimate }\end{array}$ & 2.78583 & -0.55991 & $18.64533^{* * *} *$ & $3.79637 * * *$ & -6.86945 & 2.32712 & -0.21522 \\
\hline & $\begin{array}{l}\text { Standardized } \\
\text { Estimate }\end{array}$ & 0.02197 & -0.00347 & 0.14415 & 0.05585 & -0.04230 & 0.02387 & -0.00195 \\
\hline \multirow{2}{*}{$\begin{array}{l}\text { Personal } \\
\text { income } \\
(1000 \mathrm{KRW})\end{array}$} & $\begin{array}{l}\text { Parameter } \\
\text { Estimate }\end{array}$ & $-0.00261 * * *$ & $-0.00460 * * *$ & $-0.00170 * * *$ & $-0.00113^{* * *}$ & -0.00408 & $-0.00252 * * *$ & $-0.00303^{* * *}$ \\
\hline & $\begin{array}{l}\text { Standardized } \\
\text { Estimate }\end{array}$ & -0.08399 & -0.09005 & -0.06353 & -0.08052 & -0.08219 & -0.09108 & -0.09329 \\
\hline \multicolumn{2}{|c|}{ R-Square } & 0.0666 & 0.0689 & 0.0730 & 0.0754 & 0.0600 & 0.0742 & 0.0727 \\
\hline \multicolumn{2}{|c|}{ RMSE } & 37.92284 & 62.24887 & 32.56091 & 17.13047 & 60.84657 & 33.61702 & 39.5327 \\
\hline \multicolumn{2}{|c|}{ AIC } & 25302.18 & 28750.47 & 24241.49 & 19772.69 & 28591.93 & 24463.59 & 25586.27 \\
\hline
\end{tabular}

RMSE, root mean square error; AIC, akaike information criteria.

$P$ value: $*<0.1, * *<0.05, * * *<0.001$. 
소득의 경우 치과보존과를 제외한 모든 과에서 음의 영 향력을 보이고 있어, 소득이 감소하는 지역일수록 단국 대학교 치과병원을 방문하는 환자 수가 많은 것으로 나 타났다. 결과적으로 과별로 조금씩 특성의 차이가 있으 나 단국대학교 치과병원에서 가까울수록 방문자가 증가 하며 번화한 지역보다는 주로 농촌지역의 고령 환자들 이 주로 방문하는 경향이 강한 것으로 판단된다.

\section{고찰}

본 연구에서는 대학 부속 치과병원에 내원하는 환자 들의 지리적 분포가 각 과별로 그 특성이 다를 것으로 가정하여, 지역별 환자 수, 성별, 나이 등을 변수로 하여 회귀 분석 및 공간지리가중 회귀 분석을 시행하였다. 대 학 부속 치과병원은 개인 병원에 비해 훨씬 많은 종류 의 치료를 제공하며, 대부분의 진료는 그에 전문화된 각 과별로 수행된다. 일반인들은 개인 병원에는 가까운 거 리와 편리함으로 인해 방문할 확률이 높고, 응급 상황 이나 방대한 수술을 요하는 경우에는 대학 부속 치과병 원을 방문할 가능성이 더 높다. 따라서, 저자들은 이렇 게 대학 부속 치과병원에 내원하는 환자들의 공간적 분 포를 분석해보는 것이 흥미로울 것이라고 생각하였다. 일반적인 개인병원과는 달리 진료 비용이나 대기 시간 등등에서 환자 불편함이 높고 또한 다양한 질환을 과별 로 받아야 한다는 제한이 있음에도 불구하고 대학병원 에 내원하는 환자에게는 그에 맞는 이유가 있을 것으로 사료되었으며, 그러한 이유는 각 진료과에 따라 다를 것 으로 추정했다. 연구 결과 각 과별로 특성은 상이하게 드러났으며, 통계 분석을 통해 이러한 차이 중 유의적 인 부분도 나타났다. 각 지역의 모형 영향력을 보여주는 $\mathrm{LocalR}^{2}$ 값은 일정거리 이상을 넘어가게 되면 높아지는 경향을 보이고 있다. 이는 방문환자수가 없는 지역도 0 으로 포함하여 분석을 진행하였기 때문으로 판단된다. 이러한 결과는 향후 전향적 연구를 통해 개선되어야 할 부분으로 사료된다. 또한 공간지리가중회귀분석에서 개 인소득의 경우 시도별 소득밖에 존재하지 않아 적용할 수가 없었으며, 환자의 개인별 특성을 반영하기에는 다 소 무리가 있어 향후 다양한 변수 구축을 통한 추가적인 분석진행이 요구된다.

흥미롭게도 치과보존과와 치과교정과에서는 다른 과 와 다른 환자 내원 양상이 관찰되었는데, 치과보존과의 경우 개인치과에서 진료를 거부하였거나 대학병원으로
협진 의뢰를 보냈을 가능성이 높은 것으로 사료된다. 현 행 치과 보험 제도 상 신경치료와 같은 경우는 수가 책 정이 비현실적으로 낮게 되어 있어 개인 의원에서는 진 료를 회피했을 가능성을 배제할 수 없으며 또한 발치를 권유 받은 환자들이 치아를 유지하고자 대학병원에 내 원하였을 가능성도 있다. 치과교정과의 경우는 전술한 것처럼 장기간 진료를 해야 하는 진료 특성 상 접근성이 우수한 지역의 환자들이 선택했을 것으로 사료되나, 이 에 대한 정확한 분석을 위해서는 좀더 많은 정보가 수집 되어야 할 것으로 사료된다.

이전의 GIS 기반의 보건 연구는 암이나 응급 외상 같 은 특정 질환이나 현상의 단순한 공간적인 분포에 초점 을 맞추었다. ${ }^{6,17,18}$ 하지만 이러한 단순한 지리적 정보의 정리 수준에서 한 단계 진보하여 최근 치과 학계 내에서 는 Tennant와 Kruger 등이 치과의료 공급 위치나 치과 질환의 공간적 분포와 같은 지리와 연관된 여러 연구를 집중적으로 발표하였다. ${ }^{12,19,20}$ 하지만 이러한 외국의 사 례와는 달리 국내에서는 이러한 연구가 전무한 실정이 다. 특히 본 연구에서는 대학부속 치과병원에 대한 특화 된 환경을 분석하기 위해 대학병원에 내원하는 환자들 의 거주지 지리적 분석을 시행하였으며 이러한 접근법 은 학문적으로 최초의 시도라는 점에서 그 의미가 있다.

본 연구에서 시행한 공간지리가중회귀분석(GWR: Geographically Weighted Regression)은 공간통계 분석 기법으로, 국지적 차원에서 회귀계수를 추정한다는 점 에서 기존의 ordinary least square (OLS) 회귀모형과 차 이가 있다. 공간지리가중회귀모형은 변수 간의 관계를 추정하는 회귀계수가 지역별로 다르다는 전제 하에 분 석이 진행된다. 지역간 거리 가중행렬을 이용하여 지리 적 위치에 따른 변수에 대한 각 지역별 회귀 계수를 추 정하는 것이다. 공간지리가중회귀분석은 모수를 추정할 때의 원리가 OLS 방식과 동일하기 때문에 가중최소자 승법으로 볼 수 있으나, 가중치가 연구대상지역 내의 위 치에 따라 달라진다는 점에서 그 차이가 있다. OLS 회 귀분석은 연구지역내의 유사성을 전제로 규칙성의 발견 을 추구하지만 공간지리가중회귀모형은 연구지역내의 이질성을 전제로 하여 예외적 현상을 찾는데 그 차이가 있다. ${ }^{21}$

본 연구는 공간적 분석의 대상이 환자군 자체라는 점 에서 다른 연구들과는 차별화되며, 이는 치과 영역에서 GIS를 이용하는 새로운 접근법이다. 본 연구에서 저자 들은 환자군과 진료과, 도로와의 접근성, 나이, 성별, 사 
회적 소득 등과의 관계를 알아보았고, 그 결과 흥미로운 결과들을 얻을 수 있었다. 하지만 본 연구의 한계점으로 는 데이터가 후향적으로 집계된 정보인 관계로 환자들 의 지리 정보가 부정확하게 기입된 경우가 상당히 많았 고, 환자들의 내원 이유, 이동 소요 시간, 비용 등에 대한 정보를 얻을 수 없었다. 향후 전향적으로 이러한 부분에 대한 연구가 필요할 것으로 사료된다. 또한 단일 병원에 대한 분석으로 제한되어 수도권 등 다른 주요 지역 환자 들의 분포가 고려되지 않았다는 한계가 존재한다. 따라 서 타 지역의 대학부속 치과병원의 환자 분포와 비교하 는 분석을 시행한다면 지역별 특성에 따른 환자 분포의 이해와 더욱 객관적인 결론을 얻을 수 있을 것이다.

\section{결론}

지리 정보 체계를 이용한 치과병원에 과별로 내원한 환자를 분석하여 얻어진 결과를 통해 치과 질환의 진단, 치료 계획, 병인론적 이해에 도움이 될 것으로 기대되며 특히 진료 과목별로 다양한 양상을 보인 점을 고려하여 좀더 세분화되고 특화된 공중구강보건의 향상에 기여할 수 있을 것으로 사료된다.

\section{Acknowledgements}

이 논문은 2011년도 정부(교육부)의 재원으로 한국 연구재단의 지원을 받아 수행된 기초연구사업임(No. 2011-0010739).

\section{ORCID}

Hyun-Tae Joo http://orcid.org/0000-0001-8575-2196

Byungjoon Jeong http://orcid.org/0000-0003-14030131

In-Woo Cho http://orcid.org/0000-0003-4985-3816

Hyun-Seung Shin http://orcid.org/0000-0002-14109731

Mi-Hwa Lim http://orcid.org/0000-0002-3962-1918

Jung-Chul Park http://orcid.org/0000-0002-2041-8047

\section{References}

1. Horner MW, Mascarenhas AK. Analyzing location- based accessibility to dental services: an Ohio case study. J Public Health Dent 2007;67:113-8.

2. Caprarelli G, Fletcher S. A brief review of spatial analysis concepts and tools used for mapping, containment and risk modelling of infectious diseases and other illnesses. Parasitology 2014;141:581-601.

3. Naves LA, Porto LB, Rosa JW, Casulari LA, Rosa JW. Geographical information system (GIS) as a new tool to evaluate epidemiology based on spatial analysis and clinical outcomes in acromegaly. Pituitary 2015;18:8-15.

4. McGuire S, Kruger E, Tennant M. Travel patterns for government emergency dental care in Australia: a new approach using GIS tools. Aust Dent J 2011; 56:389-93.

5. Sun W, Gong J, Zhou J, Zhao Y, Tan J, Ibrahim AN, Zhou Y. A spatial, social and environmental study of tuberculosis in China using statistical and GIS technology. Int J Environ Res Public Health 2015;12:1425-48.

6. Goli A, Oroei M, Jalalpour M, Faramarzi H, Askarian $\mathrm{M}$. The spatial distribution of cancer incidence in fars province: a GIS-based analysis of cancer registry data. Int J Prev Med 2013;4:1122-30.

7. Kim YS. Development of emergency medical transprotation system using GIS (Geographic Information System). Korean J Public Health 1996;22:193-203.

8. Lee HY, Park MY. Analysis of the emergency medical serviced area using GIS: the case of Seoul. J Korea Assoc Geogr Inf Stud 2004;12:193-209.

9. Lee TS. Emergency medical system based on GIS. Korean Assoc GEO 1996;4:43-54.

10. Shin H, Lee S. Factors affecting spatial distance to outpatient health services. Korean J Health Policy Adm 2011;21:23-43.

11. Joo SM, Lee KH, Choi JH. To identify the vulnerable areas of emergency medical services for Daegu city in 2012. J Daegu Gyeongbuk Dev Inst 2012;11: 1-9.

12. Tennant M, Kruger E, Shiyha J. Dentist-to-population and practice-to-population ratios: in a shortage environment with gross mal-distribution what should rural and remote communities focus their attention on. Rural Remote Health 2013;13:2518. 
13. Derbi HA, Kruger E, Tennant M. Incidence of oral cancer in Western Australia (1982-2009): trends and regional variations. Asia Pac J Clin Oncol 2014 Jun 17. doi: 10.1111/ajco.12205. [Epub ahead of print].

14. Kim HJ, Hyun HK, Kim YJ, Kim JW, Jang K'T, Lee SH, Hahn SH, Kim CC. A study of new-patient distribution and the motivies for visiting in the Department of Pediatric Dentistry at Seoul National University Dental Hospital. J Korean Acad Pediatr Dent 2011;38:25-32.

15. Park KL. An analysis on the characteristics of dental clinic distribution in Busan area using geographical information system. Kosin Med J 2006;21:10818.

16. Korean Statistical Information Service. Per capita personal income per administrative district. Available from: http://kosis.kr/statHtml/statHtml. do?orgId=101\&tblId=DT_1C65 (updated 2015 Jul 6).

17. Krishnatreya M, Saikia A, Kataki A, Sharma J, Ba- ruah M. Variations in the spatial distribution of gall bladder cancer: a call for collaborative action. Ann Med Health Sci Res 2014;4:S329-31.

18. Walker BB, Schuurman N, Hameed SM. A GISbased spatiotemporal analysis of violent trauma hotspots in Vancouver, Canada: identification, contextualisation and intervention. BMJ Open 2014;4:e003642.

19. Tennant M, Kruger E. Turning Australia into a 'flat-land' : what are the implications for workforce supply of addressing the disparity in rural-city dentist distribution? Int Dent J 2014;64:29-33.

20. Tennant M, Kruger E. Building a stronger child dental health system in Australia: statistical sampling masks the burden of dental disease distribution in Australian children. Rural Remote Health 2014;14:2636.

21. Jo DG. GIS and geographically weighted regression in the survey research of small areas. Surv Res 2009;10:1-19. 


\title{
Geographic information system (GIS) 이용한 대학치과병원에 내원하는 환자들의 공간적 분포의 분석
}

\author{
주현태 ${ }^{1}$, 정병준 $^{2}$, 조인우 $^{2}$, 신현승 $^{2}$, 임미화 ${ }^{3}$, 박정철 $^{2 *}$ \\ ${ }^{1}$ 한양대학교 일반대학원 도시및부동산경제연구실 \\ ${ }^{2}$ 단국대학교 치과대학 치주과 \\ ${ }^{3}$ 단국대학교 사회과학대학 도시계획/부동산학부
}

목적: 이 연구의 목적은 단국대학교 부속 치과병원에 내원하는 환자의 거주지를 지리 정보 체계를 이용하여 분석해보 고 치과의 각 전문과목 별로 환자 거주지의 지리적 특성을 분석하여 위험요소를 평가하고 치과 질환의 예방에 도움을 주기 위함이다.

연구 재료 및 방법: 2007년에서 2014년까지 단국대학교 치과병원의 구강내과, 구강악안면외과, 소아치과, 치과교정과, 치과보존과, 치과보철과, 치주과에 내원한 환자의 성별, 평균연령, 톨게이트까지의 거리 등을 이용하여 회귀분석을 진 행하였고, 방문자수의 특성을 변수로 하여 자료를 구축한 후, 공간지리가중회귀분석을 진행하였다.

결과: 시각화된 환자 자료 분석 결과 환자의 내원은 전국적인 분포 양상을 보였고, 과별로 약간의 분포 차이가 있었다. 단국대학교 치과병원에서 가까울수록 방문자가 증가하며, 번화한 지역보다는 주로 농촌지역의 고령 환자들이 방문하 는 경향이 강한 것으로 나타났다.

결론: 본 연구에서 공간지리가중회귀분석을 이용하여 환자군과 진료과, 도로와의 접근성, 나이, 성별, 사회적 소득 등 과 관계가 있음을 알 수 있었으며 정확한 상관관계를 규명하기 위해서는 다른 치과병원에 내원한 환자의 정보를 포함 한 연구가 필요하다.

(구강회복응용과학지 2015;31 (4):283-93)

주요어: 지리 정보 체계; 치과 질환; 역학

*교신저자: 박정철

(31116) 충남 천안시 동남구 단대로 119 단국대학교 치과대학 부속치과병원 치주과

Tel: 041-550-1931 | Fax: 303-3442-7364 | E-mail: periopark@dankook.ac.kr

접수일: 2015년 7월 6일 | 수정일: 2015년 9월 8일 | 채택일: 2015년 9월 14일 